\title{
Fiscalidad real y fiscalidad municipal en Castilla durante el siglo XVII: el caso de Madrid
}

\author{
Real and municipal taxation in Castile during \\ the $17^{\text {th }}$ century: the case of Madrid
}

\author{
JOSÉ IGNACIO ANDRÉS UCENDO \\ Universidad del País Vasco
}

\section{RESUMEN}

El presente artículo analiza las relaciones entre la fiscalidad real y municipal en Castilla a través del estudio del caso de Madrid en el

siglo XVII. Tras la introducción, la segunda parte describe los principales impuestos reales cobrados en la ciudad, mientras que la tercera analiza los impuestos municipales y la cuarta

los impuestos reales transferidos a la villa a cambio de servicios monetarios. La quinta parte ofrece la serie de la recaudación de los impuestos reales, municipales y los transferidos al ayuntamiento y permite observar que la importancia fiscal de Madrid para la corona se redujo en la segunda mitad

del siglo, aunque a cambio creció su papel como suministradora de servicios. En conjunto, las sumas tributadas por los madrileños crecieron a lo largo del siglo, como también se muestra en la última parte, donde se estudia la trayectoria de la carga tributaria real entre 1621 y 1700.

PALABRAS CLAVE: Fiscalidad real, Fiscalidad municipal, Madrid, España moderna

Códigos JEL: E65, H71, N13, N23, N43, N93

\section{ABSTRACT}

This article studies the interrelation between royal and municipal taxation in Castile during the 17th century through the analysis of the case of Madrid. After the introduction, the second part describes the main royal taxes levied in the city, while the third studies municipal ones. The fourth part deals with those royal taxes transferred by the Crown to Madrid after 1653 in return for the substantial monetary services provided. These different taxes are shown at an aggregate level in fifth part. The series obtained shows how while the importance of Madrid as a source of fiscal revenues for the Crown fell during the second half of the century, its role as supplier of monetary services aroused. As a whole, the sums paid by the capital inhabitants both to the royal and municipal treasuries grew throughout the century. Finally, the sixth part discusses the series after deflating it by New Castile price index between 1621 and 1700 .

KEY WORDS: Royal Taxation, Municipal Taxation, Madrid, Modern Spain

JEL Codes: E65, H71, N13, N23, N43, N93. 


\section{Introducción ${ }^{1}$}

$\mathrm{E}$ l estudio del impacto de la fiscalidad sobre la economía y la sociedad castellanas del siglo XVII es uno de los temas más debatidos por la historiografía de nuestro país. Las investigaciones de las últimas décadas, que se suman a trabajos clásicos de autores como M. Artola y A. Domínguez Ortiz, han reconstruido las pautas de la política fiscal de los Austrias menores y han presentado las series recaudatorias de varias de las principales fuentes de ingresos del fisco regio, como los servicios de millones y los cuatro unos por ciento ${ }^{2}$. También se ha puesto de relieve la necesidad de analizar otros aspectos para una mejor comprensión de las repercusiones de la fiscalidad, como los contrastes entre el peso de la carga fiscal en el mundo urbano y el rural, el papel de los donativos y el desarrollo de figuras como los administradores e intendentes, y de prácticas como el fraude fiscal o las ventas y enajenaciones del patrimonio real ${ }^{3}$. En este contexto, uno de los aspectos que más interés ha despertado en los últimos años ha sido el análisis de los vínculos existentes entre la Hacienda Real y las haciendas municipales. Éstas, tras los trabajos de las dos últimas décadas, han dejado de ser, como ha señalado $\mathrm{O}$. Rey, las grandes desconocidas de nuestra historia financiera ${ }^{4}$.

Los estudios sobre esta cuestión han revelado estrechas relaciones entre la fiscalidad real y la municipal. Los concejos tenían un importante papel en la cobranza de varios de los principales impuestos de la Corona; además, ésta solicitaba con frecuencia préstamos y donativos a aquéllos. Para afrontar el pago de tales préstamos y donativos, los ayuntamientos recurrían al crédito municipal y, a cambio, obtenían el control, total o parcial, de algunos dacios reales y el derecho a imponer arbitrios (a menudo sisas y cargas monetarias sobre el consumo), con los que pagaban a sus acreedores. Estas operaciones implicaban un trasvase de recursos de la Real Hacienda a los municipios, del que salieron fortalecidas las oligarquías locales, principales gestoras y beneficiarias del sistema, aunque en contrapartida provocaron la expansión de la deuda municipal, a menudo financiada mediante impuestos indirectos.

[Fecha de recepción del original, septiembre de 2005. Versión definitiva, marzo de 2006]

1 Este artículo se ha realizado gracias al proyecto de investigación "Fiscalidad, economía y política en Castilla durante los reinados de Felipe IV y Carlos II", financiado por el Ministerio de Educación y CienciaFEDER, BHA 2002-01942. Deseo agradecer a Emiliano Fernández de Pinedo y a Ramón Lanza, así como a los evaluadores anónimos de Investigaciones de Historia Económica, las sugerencias y observaciones realizadas a versiones previas del mismo.

2 Domínguez Ortiz (1960); Artola (1982); García Sanz (1991); Pulido (1996); Gelabert (1997); Sánchez Belén (1996); Andrés Ucendo (1999) y (2001), y Fortea (2000).

Saavedra (1993); Sebastián y Vela (1993); Cárceles de Gea (2000), y Marcos Martín (2003) y (2004).

Rey (2004), pp. 241-242. 
Aparte del clásico artículo de F. Ruiz Martín sobre las técnicas usadas por los ayuntamientos para recaudar los tributos, disponemos en la actualidad de trabajos sobre las haciendas municipales de Córdoba y Granada en el siglo XVI, y las de Valladolid, Málaga y Sevilla en el XVII, a los que se añade el libro de I. Mugartegui sobre las haciendas locales vascas en la Edad Moderna ${ }^{5}$. Hay acuerdo en señalar que durante los siglos XVI y XVII la deuda municipal experimentó un notable crecimiento, lo que creó un problema que atrajo la atención de la monarquía borbónica, según demuestra C. García García en su libro sobre las reformas administrativas y fiscales de los municipios entre 1743 y $1845^{6}$. Pero la expansión de la deuda municipal no ha sido el único aspecto de las haciendas locales analizado por los historiadores; éstos también han atendido a otras cuestiones, como el papel de los bienes de propios. Los trabajos J. M. de Bernardo sobre éstos en la ciudad de Córdoba a finales del siglo XVII son ejemplo de ello ${ }^{7}$.

Por lo que se refiere a Madrid, la hacienda de la villa en el siglo XV ha sido analizada por I. Monturiol, mientras que C. de la Hoz ha descrito varias facetas de la fiscalidad de la capital en el siglo XVII, que muestran los estrechos vínculos entre las fiscalidades real y municipal ${ }^{8}$. El propósito de las líneas que siguen es ayudar a comprender mejor tales relaciones, así como el papel de Madrid en el sistema fiscal castellano, mediante la presentación de las series de valores de las recaudaciones de alcabalas, cientos y servicios de millones, y de los impuestos municipales cobrados en la ciudad entre 1601 y 1700.

Tras el definitivo asentamiento de la corte en la ciudad en 1606, Madrid se convirtió en la capital de uno de los distritos fiscales más importantes del país, motivo por el cual la segunda parte del artículo describe la organización establecida para la cobranza de las alcabalas, cientos y servicios de millones. Se han escogido estos tributos, el núcleo de lo que en el siglo XVIII serían las Rentas Provinciales, porque las cantidades recaudadas por los mismos representaban alrededor del 50-55 por 100 de los ingresos fiscales ordinarios de la Corona en el Seiscientos; por tanto, pueden considerarse representativos de la trayectoria de la fiscalidad castellana. Además de ellos, los madrileños debían afrontar el pago de los impuestos municipales, descritos en el tercer apartado, con los que se atendían las necesidades ordinarias del municipio. Sin embargo, debe subrayarse que, según ha recordado C. de la Hoz, desde fechas tempranas el ayuntamiento también usó los impuestos municipales para 
atender necesidades de la Monarquía ${ }^{9}$. En estos casos, Madrid ofrecía servicios a la Corona y, para reunir las sumas comprometidas, emitía los llamados "efectos de villa"10. A cambio, la Monarquía daba autorización para que se introdujesen nuevos impuestos municipales, cuyas recaudaciones se destinaban sobre todo a pagar a los compradores de los "efectos" sus intereses. Estas operaciones alcanzaron su mayor desarrollo entre 1653 y 1678. Como resultado, Madrid no sólo obtuvo licencia para ampliar el número de los tributos municipales, sino que, según se verá en la cuarta parte, la Corona transfirió a la villa la mayor parte de los servicios de millones recaudados en la provincia. Tras lo anterior, en la quinta parte se muestran las recaudaciones de las alcabalas, cientos, millones, impuestos municipales y servicios de millones transferidos a la capital, las cuales revelan que la carga tributaria que recaía sobre los madrileños, en términos nominales, creció de modo notable en el transcurso de la centuria. En el sexto y último apartado se presenta la evolución de este indicador en términos reales. El artículo se cierra con unas breves conclusiones.

\section{La fiscalidad real en Madrid: millones, alcabalas y cientos}

Ya hemos señalado en la introducción el peso de los millones, las alcabalas y los cientos en el conjunto de los ingresos fiscales de la Corona. De particular importancia fueron desde 1635 los servicios de millones, al superar con holgura su recaudación anual el monto del encabezamiento de alcabalas, lo que les convirtió en la principal fuente de ingresos fiscales de la Monarquía en las décadas centrales del siglo XVII ${ }^{11}$. En la cobranza de los servicios de millones en Madrid se aplicaron las normas establecidas en las condiciones de los servicios, por lo que no existen diferencias de relieve entre la organización creada en la villa para recaudarlos y la existente en el resto de las ciudades y villas del reino, si bien se aprecian algunas novedades, entre las cuales la más destacada fue la transferencia de la mayor parte de los servicios de millones cobrados en la ciudad y en la provincia de Madrid a la villa, en contrapartida de los numerosos servicios concedidos por ésta a la Corona entre 1653 y 1678.

En cuanto a las alcabalas y los cientos, en su cobranza se usaron las técnicas recaudatorias empleadas en el resto del reino. Al igual que en las ciudades y villas castellanas durante el XVII, las alcabalas estuvieron encabezadas ${ }^{12}$, y el municipio

\footnotetext{
10 Según el criterio adoptado por Mauro Hernández en su libro sobre las oligarquías madrileñas en la Edad Moderna, los "efectos de villa" pueden considerarse como meros censos consignativos contra la villa de Madrid (Hernández, 1995, pp. 123 y 126).

11 Andrés Ucendo (1999), p. 29.

12 Archivo de la Villa de Madrid (AVM, en adelante), Secretaría, 3-61-34.
} 
recurrió a este método para pagar también los cientos, de modo que ya desde 1642, y posiblemente desde antes (aunque no hemos podido encontrar constancia documental de ello), se firmaron encabezamientos conjuntos de ambos tributos ${ }^{13}$. Estos contratos se gestionaban mediante una junta presidida por el corregidor local y formada por dos comisarios, nombrados por el cabildo entre los regidores, y dos diputados de rentas, designados por los gremios ${ }^{14}$. La junta vigilaba la cobranza de alcabalas y cientos, para lo que recibía la jurisdicción necesaria, con inhibición de los alcaldes de Corte y de los Consejos, constituyendo el tribunal ante el cual se resolvían todos los pleitos y causas ${ }^{15}$.

Por último, debe reseñarse que, al igual que sucedía en otras ciudades en la misma época, como Valladolid, los gremios disfrutaban de un papel de gran relevancia en el terreno fiscal ${ }^{16}$. Ya en 1660, la villa de Madrid traspasó la cobranza del encabezamiento de alcabalas y cientos a las corporaciones ${ }^{17}$. Tras renovar los encabezamientos, los gremios, a través de sus dos diputados en la junta, llegaban a un acuerdo con la villa en virtud del cual ésta les transfería el cobro de alcabalas y cientos, quedando relevada de cualquier responsabilidad en caso de incumplimiento ${ }^{18}$.

\section{La fiscalidad municipal madrileña}

Durante la Edad Moderna, los bienes de propios y los impuestos indirectos fueron dos de las principales fuentes de ingresos de los concejos castellanos. En el caso de Madrid, las rentas de propios tuvieron poco valor en el siglo XVII. Aunque nos ha sido imposible reconstruir una serie continua para toda la centuria, gracias a la consulta de los fondos del Archivo de la Villa sabemos que en varios años de la misma el valor de los arriendos de las rentas de propios osciló entre los 5 y los 8 millones de maravedíes, cifra pequeña si se compara con el rendimiento de los impuestos municipales y de los servicios de millones transferidos (véase el Apéndice 1) ${ }^{19}$.

El escaso valor de las rentas de propios explica que el ayuntamiento de la capital recurriera a los impuestos sobre el consumo para financiar sus actividades. Así nacieron las llamadas "Sisas Municipales", nombre con el que los contadores

AVM, Secretaría, 2-448-1.

AVM, Secretaría, 2-448-1; 2-498-6 y 3-67-21.

AVM, Secretaría, 3-67-21 y 2-498-6.

Capella y Matilla (1957), pp. 70-75. Para Valladolid, véase Gutiérrez Alonso (1988), pp. 399-400.

AVM, Secretaría, 3-67-19.

AVM, Secretaría, 3-67-18; 3-67-21 y 2-213-48.

AVM, Secretaría, 4-333-20; 3-6-46; 3-6-50; 3-67-71 y 3-67-78. 
madrileños se referían a los impuestos indirectos de origen municipal cobrados por la villa ${ }^{20}$. Gracias al artículo de C. de la Hoz sobre el sistema fiscal madrileño, sabemos que durante el siglo XVII se llegaron a cobrar nada menos que 22 tributos municipales, que pueden dividirse en dos grupos. El primero, de nueve tributos, se introdujo para atender necesidades propias del concejo (las sisas Ordinarias, la sisa de la Sexta Parte, la sisa del Vino de la Plaza, la sisa del Carnero de Fuentes, la sisa del Vino de la Cárcel, la sisa del Vino de la Salud, la sisa del Carnero de Hospitales, la sisa de la Vaca de Hospitales y los arbitrios para el Pósito). Y el segundo grupo lo formaban los otros trece tributos restantes, creados para financiar gastos no municipales como, por ejemplo, campañas militares, recibimientos y bodas reales o reformas en el palacio (sisa del Cuarto de Palacio, sisa del Vino de Lérida, sisa de la segunda blanca del carbón, sisa del Carnero de Quiebras, sisa del Vino de Olivenza, sisa de la tercera blanca del carbón, sisa de la segunda onza del azúcar, sisa del Vino Bajada de Medidas, sisa de la cuarta blanca del carbón, sisa del Vino del Error de Medidas, sisa del Cacao y Chocolate, Renta del Hierro y Metales y Primer cuartillo de vino) ${ }^{21}$.

Como se ha indicado más arriba, en estos casos el municipio ofrecía un servicio monetario a la Corona, la cual, en contrapartida, le autorizaba a imponer nuevos gravámenes sobre el consumo. Por citar un ejemplo representativo, en 1657 el municipio sirvió con 100.000 ducados para el sitio de Olivenza; para reunir esta suma el concejo emitió "efectos de villa", autorizándole a cambio la Corona a introducir la cobranza de 19 maravedíes por arroba de vino para pagar a los "efectistas". De este modo, el ayuntamiento encontró un método que le permitía atender las necesidades de la Corona a través de un grupo de impuestos indirectos. Si a esto se añade que el interés devengado por los "efectos" era muy ventajoso, el atractivo de estas operaciones es fácil de comprender y no resulta extraño, por tanto, que se recurriera a ellas con tanta frecuencia ${ }^{22}$.

Estos tributos suponían un conjunto de sisas y gravámenes monetarios con los que se cargaba, sobre todo, el precio del vino, las carnes y el aceite y, en menor medida, el carbón, el azúcar, la nieve y el hielo, el jabón, la cera, los pescados, el cacao y el chocolate, lo que encarecía sensiblemente el precio de varios productos esenciales en la dieta de los madrileños. A partir de los datos de C. de la Hoz, los recargos sobre el vino, la carne y el aceite debidos a los tributos del primer grupo llegaron a ascender

20 En sentido estricto, las sisas eran un medio de recaudar impuestos indirectos, aunque en la documentación municipal el término se empleaba como sinónimo de los impuestos sobre el consumo (De la Hoz, 1988, p. 383).

21 De la Hoz (1988), pp. 377-379.

22 Los "efectos de villa" devengaban un 10 por 100, reducido al 8 en 1669, al 5 en abril de 1680 y, por último, al 4 por 100 en 1686. A modo de comparación, el interés de los censos ordinarios se redujo al 5 por 100 desde 1621 (Hernández, 1995, p. 23; Peñasco, 1891, p. 43, y AVM, Secretaría, 3-297-10). 
a 67 maravedíes por arroba de vino, 3,5 reales por cabeza de carnero, 2 maravedíes por libra de carnero, 1,5 reales por cabeza de macho, 8,5 maravedíes por cabrito, 6 maravedíes por libra de vaca y 2 maravedíes por libra de cerdo, a los que deben sumarse otros 129,5 maravedíes por arroba de vino, 1 maravedí por libra de vaca, 3 maravedíes por libra de carnero y 1,5 reales por carnero, recaudados por las sisas municipales aplicadas para necesidades no municipales del segundo grupo ${ }^{23}$.

\section{Los servicios de millones transferidos a Madrid}

Ante sus cuantiosas necesidades de recursos, acentuadas por las dificultades para obtener crédito en buenas condiciones por el progresivo empeoramiento de su sistema financiero, la Corona solicitó frecuentes servicios a Madrid en las décadas centrales del siglo. Aunque el ayuntamiento recurriera, según lo indicado en el apartado anterior, a la emisión de "efectos" situados sobre las recaudaciones de varios impuestos municipales para atender tales peticiones, la principal novedad del período radicó en que la Corona también transfirió al ayuntamiento la mayor parte de los servicios de millones recaudados en la ciudad y en los municipios de la provincia. El proceso comenzó en 1653, cuando Madrid obtuvo el servicio de los 8.000 soldados a cambio de 220.000 ducados, y se prolongó hasta $1678^{24}$. Al final de este período, Madrid acaparaba la cobranza de los 8.000 soldados ya citados más los servicios de las carnes, los tres millones, las quiebras y los gravámenes monetarios del vino de los 24 millones, junto con las sisas de las carnicerías, el rastro y el aceite del mismo servicio; en tanto que la Monarquía apenas retenía la sisa de la octava parte del vino consumido en la ciudad y provincia y las cargas monetarias sobre el vino de los 24 millones en la provincia. Según la terminología de los contadores madrileños, los servicios que acabamos de mencionar eran "empeñados" por la Corona al municipio, lo cual significaba que la villa controlaba su gestión, arrendándolos como los impuestos municipales hasta que se redimieran los principales de los "efectos". Así nacieron las llamadas "Sisas Reales", término usado en la documentación para referirse a aquellos servicios de millones transferidos por la Corona a la ciudad a cambio de servicios monetarios.

De la Hoz (1988), pp. 372-375.

AVM, Secretaría, 2-297-31 y 2-444-48. Madrid obtuvo el servicio de las carnes en 1656 y 1661; el de los tres millones en 1657; la cobranza del vino de las quiebras de millones en 1665; las sisas de las carnes y el aceite de los 24 millones en 1667 y, por último, los gravámenes monetarios del vino de los 24 millones en 1678 (De la Hoz, 1988, p. 381). 
A lo anterior debe añadirse que, en 1673, Madrid obtuvo, previa entrega de servicios por un valor de casi 1,7 millones de ducados ${ }^{25}$, el valor de la Renta del Tabaco en la capital y su provincia, si bien esta fuente de ingresos presentaba dos peculiaridades dignas de mención. En primer lugar, en este caso la villa no recibió la gestión y cobranza del tabaco. La Renta General del Tabaco del reino estaba arrendada y se optó por permitir que el arrendador de la misma en Madrid siguiera recaudándola para ceder luego su valor al ayuntamiento de la capital a fin de que éste pagara los intereses a los "efectistas" 26 . En segundo lugar, debe recordarse que el arriendo del tabaco, aunque se introdujera como un medio de pago del servicio de los 2,5 millones votado en 1632, acabó convirtiéndose en una renta independiente, separada de los servicios de millones ${ }^{27}$.

A finales del siglo, la villa de Madrid controlaba el 81 por 100 de los servicios de millones recaudados en la provincia, lo que constituye buena prueba de la importancia de la transferencia de los servicios al ayuntamiento de la capital. Si sumamos al valor global de las pagas de millones en Castilla las recaudaciones controladas por Madrid, se observa que el peso de éstas creció, desde el 3 por 100 del total resultante en 1655-1659, hasta el 21-22 por 100 en los últimos quince años del siglo, lo que significaba que, hacia 1700, la villa controlaba algo más de la quinta parte de las cantidades pagadas por los castellanos en concepto de millones, si bien a cambio había servido a la Monarquía con cuantiosas sumas. Se ha estimado que, entre 1642 y 1680, Madrid otorgó servicios a la Real Hacienda por un valor de 16 millones de duca$\operatorname{dos}^{28}$, cifra que constituye una elocuente muestra de la estrecha colaboración entre las oligarquías urbanas del país y la Monarquía en las décadas centrales del siglo, tras la salida de Olivares ${ }^{29}$. La mayor parte de tales servicios, unos 15 millones de ducados, se realizó entre 1653 y 1678, y para reunirlos el ayuntamiento recurrió al crédito municipal, emitiendo "efectos de villa". De esos casi 15 millones de ducados, 2,5 millones (el 17 por 100) se situaron sobre varios impuestos municipales introducidos en el transcurso del período, mientras que otros 7,3 (el 49 por 100) recibieron como consignación los servicios de millones cedidos a la villa por la Real Hacienda, y otros 3,1 (el 21 por 100), la Renta del Tabaco ${ }^{30}$.

De lo anterior se deduce que la importancia de Madrid como fuente de servicios para la Corona en las décadas centrales del siglo dependió de la introducción de nuevos impuestos municipales y, sobre todo, de la cesión a la villa de la mayoría de los

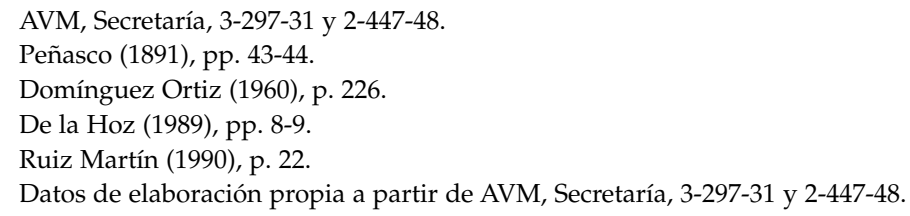


CUADRO 1

PESO DE MADRID EN EL TOTAL RECAUDADO POR ALCABALAS, CIENTOS Y MILLONES, SIGLO XVII (porcentajes)

\begin{tabular}{ccccc}
\hline Quinquenios & Madrid (a) & Quinquenios & Madrid (a) & Madrid (b) \\
\hline $\mathbf{1 6 0 1 - 1 6 0 5}$ & 2,3 & $\mathbf{1 6 5 1 - 1 6 5 5}$ & 11,0 & 12,0 \\
$\mathbf{1 6 0 6 - 1 6 1 0}$ & 4,5 & $\mathbf{1 6 5 6 - 1 6 6 0}$ & 10,0 & 12,0 \\
$\mathbf{1 6 1 1 - 1 6 1 5}$ & 6,0 & $\mathbf{1 6 6 1 - 1 6 6 5}$ & 11,0 & 14,0 \\
$\mathbf{1 6 1 6 - 1 6 2 0}$ & 6,0 & $\mathbf{1 6 6 6 - 1 6 7 0}$ & 9,0 & 14,0 \\
$\mathbf{1 6 2 1 - 1 6 2 5}$ & 7,0 & $\mathbf{1 6 7 1 - 1 6 7 5}$ & 9,0 & 15,0 \\
$\mathbf{1 6 2 6 - 1 6 3 0}$ & 8,5 & $\mathbf{1 6 7 6 - 1 6 8 0}$ & 8,0 & 15,0 \\
$\mathbf{1 6 3 1 - 1 6 3 5}$ & 9,0 & $\mathbf{1 6 8 1 - 1 6 8 5}$ & 8,0 & 16,0 \\
$\mathbf{1 6 3 6 - 1 6 4 0}$ & 11,0 & $\mathbf{1 6 8 6 - 1 6 9 0}$ & 10,0 & 20,0 \\
$\mathbf{1 6 4 1 - 1 6 4 5}$ & 10,5 & $\mathbf{1 6 9 1 - 1 6 9 5}$ & 10,5 & 20,0 \\
$\mathbf{1 6 4 6 - 1 6 5 0}$ & 11,0 & $\mathbf{1 6 9 6 - 1 7 0 0}$ & 10,0 & 19,0 \\
\hline
\end{tabular}

Madrid (a): Participación de Madrid en las cantidades recaudadas por alcabalas, cientos y millones sin contar los millones transferidos.

Madrid (b): Participación de Madrid en las cantidades recaudadas por alcabalas, cientos y millones incluyendo los millones transferidos.

Fuentes: Apéndices 1 y 2.

servicios de millones recaudados en la ciudad y su distrito, así como del valor de la Renta del Tabaco, lo que tuvo consecuencias tanto para la Hacienda Real como para los propios madrileños.

En cuanto al primer aspecto, la aportación de la provincia de Madrid a las recaudaciones fiscales de la Corona creció de modo claro de 1606 a 1640, como se aprecia en el Cuadro 1, que relaciona las cantidades ingresadas por alcabalas, cientos y millones en la capital con el total recaudado de estos dacios en Castilla.

$\mathrm{Al}$ iniciarse el siglo, el peso fiscal de la provincia de Madrid era pequeño, comparable al de otras como Segovia o Guadalajara, representando poco más del 2 por 100 del total ingresado por alcabalas, millones y cientos. Como resultado del crecimiento de la villa en las primeras décadas de la centuria, la importancia de la capital aumentó hasta el 11 por 100 en 1636-1640, valor en el que se estabilizaron las aportaciones madrileñas entre 1646 y 1665; luego experimentaron un ligero descenso. De no haber mediado la cesión de la mayoría de los servicios de millones tras 1653, estos valores habrían sido muy superiores. La última columna del Cuadro 1 recoge el porcentaje de las recaudaciones de alcabalas, cientos y millones que habría pagado la 
capital si la Corona hubiese retenido la cobranza de todos los servicios de millones. En ese caso, la aportación madrileña al monto ingresado por los tres impuestos habría crecido del 12 por 100 en 1655 al 19 por 100 en 1695-1700, con lo que el peso de la capital habría sido análogo al de la provincia de Sevilla, la principal contribuyente al fisco regio en los siglos XVI y XVII.

En cuanto a las repercusiones sobre los habitantes de la capital del traspaso de los servicios de millones a Madrid, ya se ha señalado que, para reunir las cantidades con que servía a la Corona, el municipio emitió "efectos de villa", destinándose los impuestos municipales y los servicios de millones transferidos a pagar el principal y los intereses de los mismos. Sin embargo, ya en 1660 se advertía que el municipio apenas podía atender el pago de los citados intereses y que disponía de muy pocos caudales para redimir los principales de los "efectos", y ello por dos motivos ${ }^{31}$. Uno, porque su alta rentabilidad, si bien les garantizaba una buena acogida, provocaba a cambio el aumento de la carga representada por los intereses; y dos, porque, a medida que crecieron las necesidades de la Corona, la villa concedió sucesivos servicios sobre los impuestos municipales y los millones transferidos, lo que dificultó aún más la posibilidad de redimir los principales. Por citar el caso quizá más elocuente, en 1674 Madrid sirvió con casi 1,7 millones de ducados sobre la Renta del Tabaco en la provincia, a los que se añadieron 400.000 más en 1675 y 1.060 .000 en el transcurso de 1677 y $1678^{32}$. Sin lugar a dudas, esto agravó el problema del endeudamiento municipal madrileño que tanto preocupó a los regidores de la villa en el siglo XVIII.

Además, la emisión de "efectos de villa" sobre los millones "en empeño" tuvo otra consecuencia para los madrileños. Como se desprende de los Apéndices 1 y 2, entre 1680 y 1689 las recaudaciones de los servicios de millones en Castilla cayeron un 45 por 100, pero en Madrid, en el mismo período, sólo se redujeron (sumando a los servicios todavía controlados por la Corona los millones transferidos a la capital) un 21 por 100: la necesidad de pagar a los "efectistas" sus intereses obligó a conservar servicios como las quiebras de millones, las carnes y los tres millones que habían desaparecido en Castilla (en 1670 los primeros y en 1686 los otros dos). Esto representaba, a escala municipal, una repetición del mismo fenómeno experimentado en el conjunto del reino con los servicios de millones después de 1626, sobre el que ha llamado la atención E. Fernández de Pinedo ${ }^{33}$. Si en dicho año la emisión de juros sobre los servicios de millones significó la perpetuación de esta figura fiscal, en Madrid, el recurso a los "efectos de villa" luego de 1653 obligó al ayuntamiento a mantener los servicios, incluso después de que algunos se suprimieran en el resto del reino.

AVM, Secretaría, 4-319-5.

AVM, Secretaría, 3-297-31 y 2-447-48.

Fernández de Pinedo (1993), p. 48. 
Los recargos sobre el consumo de vino, vinagre y aceite de las denominadas "Sisas Reales", que se suman a los citados en la segunda parte, eran cuantiosos. En conjunto, los recargos cuya cobranza se cedió a la villa ascendían, ciñéndonos a los de mayor relieve, a 135 maravedíes por arroba de vino, 202 por arroba de aceite, 272 por cabeza de carnero y 8 por libra de carnero. A éstos se añadían diversos recargos, de menor importancia, sobre la carne de vaca y el tocino ${ }^{34}$.

\section{Las recaudaciones de los impuestos municipales, millones transfe- ridos, alcabalas, millones y cientos en Madrid}

El Gráfico 1 muestra las cantidades recaudadas por impuestos municipales, millones transferidos, alcabalas, millones y cientos en Madrid entre 1621 y 1700. Aunque disponemos de las cifras correspondientes a lo ingresado por alcabalas, cientos y millones desde 1601 (véase el Apéndice 1), el gráfico comienza en 1621 porque nos ha sido imposible obtener informaciones fiables sobre los ingresos municipales de la villa en las dos primeras décadas de la centuria.

Para establecer el valor de las alcabalas se ha consultado la sección de Contadurías Generales del Archivo General de Simancas (AGS, en adelante). En concreto, se han reconstruido los encabezamientos de 1601 a 1615. En cuanto a las cifras de los demás años, dado que las recaudaciones no oscilaban demasiado, hemos optado por reconstruir los encabezamientos de Madrid (y Castilla) en una serie de años que han servido de referencia ${ }^{35}$. Para las restantes cantidades recaudadas se ha calculado una media aritmética simple de los valores de los años de referencia, por lo que, por ejemplo, las cifras de 1621, 1622, 1623 y 1624 corresponden a la media de los encabezamientos de 1620 y 1625. La bondad de este sencillo método, también usado para reconstruir las recaudaciones de las alcabalas en Castilla (Apéndice 2), puede juzgarse por el hecho de que los datos presentados en el Gráfico 1 y el Apéndice 1 son casi iguales a los del encabezamiento de alcabalas, tercias y cientos del partido de Madrid entre 1670 y 1700, conocidos gracias a los fondos del Archivo de la Villa ${ }^{36}$.

\footnotetext{
34 Calculado a partir de Andrés Ucendo (1999), pp. 116-126, y De la Hoz (1988), pp. 372-375.

35 Éstos han sido 1620, 1625, 1626, 1630, 1634, 1640, 1642, 1645, 1650, 1651, 1655, 1660, 1665, 1670, 1675, 1680, $1681,1682,1684,1685,1690,1695$ y 1700.

36 Si nos ceñimos a las alcabalas, éstas se encabezaron en 82,4 millones de maravedíes para el período 16701678 (AVM, Secretaría, 3-67-19), cantidad casi idéntica a la ofrecida en el Apéndice 1 (85 millones de maravedíes anuales). De 1679 a 1687 el encabezamiento no varió demasiado, 82 millones de maravedíes anuales, y aunque nuestras cifras son algo inferiores entre 1683 y 1687, ello se explica porque en dichos años se otorgaron varios descuentos (AVM, Secretaría, 3-67-21). Un nuevo encabezamiento de alcabalas y cientos se firmó entre 1686 y 1696 (AVM, Secretaría, 3-61-39), por 124 millones de maravedíes, valor de nuevo similar al del Apéndice 1 (126 millones de maravedíes anuales).
} 


\section{GRÁFICO 1}

INGRESOS POR ALCABALAS, CIENTOS; SERVICIOS DE MILLONES, MILLONES TRANSFERIDOS E IMPUESTOS MUNICIPALES EN MADRID, 1621-1700

(millones de maravedíes corrientes)

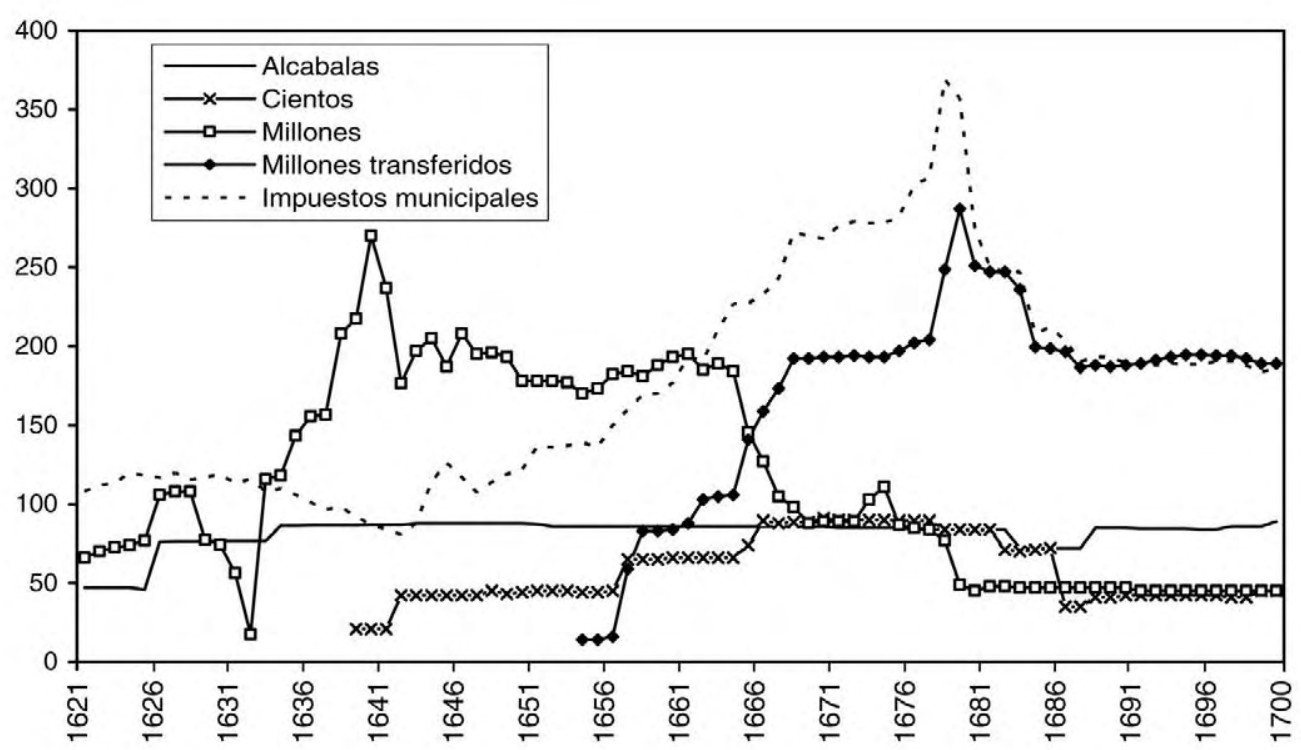

Fuentes: Apéndice 1

A comienzos del Seiscientos, las alcabalas y las tercias de la ciudad de Madrid y su partido estaban encabezadas en 21,2 millones de maravedíes anuales, valor que bajó en 1605 y 1606. El definitivo retorno de la corte a la villa en la última fecha citada espoleó una notable alza del encabezamiento hasta los 30,6 millones de maravedíes anuales en 1608. El encabezamiento madrileño volvió a subir, hasta 41 millones de maravedíes, en 1611, y en la segunda década del siglo se estabilizó en torno a 4647 millones anuales. La mayor subida de la centuria se produjo en 1626, cuando el valor del contrato creció en 30 millones, llegando a 76-77 millones de maravedíes. Por último, en 1634 hubo un nuevo aumento, rozándose los 87 millones de maravedíes, nivel en torno al cual se estabilizó el encabezamiento durante el resto del siglo (si exceptuamos los descuentos otorgados en 1683-1687).

En la trayectoria de los cuatro cientos se detectan fases bien definidas. El primero, introducido en 1639, se encabezó en 21 millones de maravedíes, cifra que se duplicó hasta los 42 millones con el segundo ciento en 1642. Con el tercero, votado en 1656, las pagas se situaron alrededor de los 65 millones y, con el cuarto y último 
ciento, que se votó en 1663, las recaudaciones se estabilizaron en torno a 85-90 millones de maravedíes. Como en el caso de las alcabalas, en la primera mitad de la década de 1680 varios descuentos redujeron el monto recaudado. A ello se sumó la rebaja a la mitad de los cuatro unos por ciento en 1686, que hizo disminuir lo ingresado en torno al 50 por 100 .

Por lo que hace a los servicios de millones, en un trabajo anterior ofrecimos la serie de las cantidades recaudadas por este concepto en la provincia de Madrid durante el siglo XVII, si bien ya entonces advertíamos que, debido a la enajenación de buena parte de las recaudaciones de los servicios al municipio, los datos estaban infravalorados ${ }^{37}$. Gracias a la consulta de los fondos del Archivo de la Villa podemos presentar ahora una nueva serie que mejora la anterior, ofreciendo una estimación más fiable del monto de las sisas reales controladas por la villa (Apéndice 1). A diferencia de las alcabalas y cientos, esta nueva serie incluye las pagas de los millones en toda la provincia de Madrid, compuesta por la capital y un conjunto de alrededor de 100 localidades situadas en los alrededores, así como en el partido de Zorita (en el sudoeste de la actual provincia de Guadalajara). No obstante, el valor de las recaudaciones de estos núcleos en el conjunto provincial era reducido (alrededor del 10 por 100) y su inclusión en nuestros cálculos no constituye un grave problema ${ }^{38}$.

En la recaudación de los servicios de millones se distinguen dos fases. La primera, de 1601 a 1653, se caracterizó por el alza de las cifras ingresadas. El asentamiento de la capital en 1606 elevó las recaudaciones desde casi 25 millones de maravedíes en 1605 a 56 en 1607. En 1626, tras la aparición del servicio de los 12 millones, la recaudación registró una subida considerable, rebasando por vez primera el umbral de los 100 millones de maravedíes. La siguiente fase alcista se desarrolló en los años treinta. Entre 1633 y 1640 lo recaudado pasó de 116 millones anuales a 269,6, siendo fruto de la introducción en 1638 de los servicios de los 8.000 soldados para el socorro de Fuenterrabía y de las quiebras de millones, así como de la unificación, en 1640, de todas las sisas y gravámenes monetarios sobre el vino, percibidos en concepto de millones, en un solo impuesto. Posteriormente, las cantidades ingresadas descendieron, aunque se mantuvieron en niveles aún muy superiores a los de la primera década del siglo ${ }^{39}$. La segunda etapa se extendió entre 1654 y 1700, y estuvo

$37 \quad$ Andrés Ucendo (1999), pp. 18-19 y 204.

38 Las diferencias respecto de la serie ofrecida en 1999 no son muchas. La más significativa afecta al período 1667-1682. En 1667, el municipio obtuvo la cobranza de las carnicerías y la sisa del aceite del servicio de los 24 millones, a las que se añadieron en 1678 más cargas del mismo servicio, como el millón del rastro, el tocino y los gravámenes monetarios sobre el vino de los 24 millones consumido en la villa. Por este motivo, en la serie de las recaudaciones de millones de Madrid del Apéndice 1 se han descontado dichos gravámenes, cuyo valor se ha incluido en los millones traspasados desde el momento en que fueron recaudados por la villa (AVM, Secretaría, 3-247-1, 3-254-1 y 3-255-1).

39 Andrés Ucendo (1999), pp. 27-28. 
presidida por la transferencia de porciones crecientes de la recaudación de los millones a cambio de varios servicios, de modo que al final del período la Corona recaudaba una parte minoritaria de este tributo, lo cual explica el descenso de los ingresos por este concepto desde los 170,2 millones de maravedíes de 1654 a los apenas 45 de $1700^{40}$.

Ya hemos indicado en el apartado anterior que el ayuntamiento de Madrid arrendaba sus principales fuentes de ingresos. La consulta de los fondos del Archivo de la Villa nos ha permitido conocer la historia de estos contratos desde 1621 y elaborar las series del Apéndice 1. Hemos recopilado las recaudaciones de la mayoría de los impuestos municipales, aunque se detectan algunas ausencias entre 1621 y 1680, por lo que las cifras atribuidas a este período están ligeramente infravaloradas ${ }^{41}$. En cuanto a los servicios de millones transferidos, que Madrid también cobraba mediante arriendos, la serie incluye las localidades de la provincia, cuyo volumen, como quedó dicho, no era demasiado elevado. El Gráfico 1 indica que, entre 1621 y 1643, lo percibido por impuestos municipales se mantuvo estable, con un descenso al final del período. Sin embargo, luego de 1644, la aparición de nuevos impuestos municipales impulsó elevó las recaudaciones desde los 88 millones de maravedíes anuales en 1643 hasta los 369 en $1678^{42}$. A esta fase alcista le sucedió una caída, entre 1680 y 1700, reduciéndose lo ingresado hasta los 185,5 millones de maravedíes anuales, por la supresión de varios gravámenes y las sucesivas rebajas en los arriendos en los años finales del siglo.

El rápido crecimiento de lo recaudado por los millones traspasados a Madrid constituye uno de los fenómenos más destacados del Gráfico 1 y del Apéndice 1 . Si los servicios de millones controlados por la capital sólo valieron 14 millones de

40 Esta caída supera la estimada por nosotros en 1999. Entonces sostuvimos que, a finales del siglo, la Corona aún controlaba el 42 por 100 de las cantidades recaudadas por millones en la provincia de Madrid (Andrés Ucendo, 1999, pp. 203-206). Pero, tras revisar la documentación municipal, queda claro que dicho porcentaje era exagerado y que, hacia 1700, el fisco regio sólo recaudaba el 18 por 100.

41 En concreto, nos faltan los valores del maravedí por libra de carne de vaca, perteneciente a las sisas del Cuarto de Palacio, desde su inicio, en 1621, hasta 1670; los de la sisa del Vino de la Cárcel, desde su introducción hasta 1651; los de la sisa del Vino de la Salud, desde su aparición en 1637 hasta 1652, y los de la sisa de la Vaca de Hospitales, desde su introducción en 1659 hasta 1680. Teniendo en cuenta estas faltas, podemos estimar que las recaudaciones de las sisas municipales del Apéndice 1 debieron de ser un 2 por 100 superiores en 1621-1629, un 6 por 100 mayores en 1630-1636 y un 15 por 100 más elevadas en 1637-1650. En 1650, nuestras cifras estarían infravaloradas en un 10 por 100, y de 1652 a 1680, entre el 2 y el 7 por 100 según los años.

42 Durante el período 1643-1678 se introdujeron las sisas del Carnero de Hospitales (en 1644), la sisa del Vino de Lérida (en 1644), la segunda blanca del carbón (en 1649), la sisa del Carnero de Quiebras (en 1656), la sisa del Vino de Olivenza (en 1657), la sisa de la Vaca de Hospitales (en 1659), la tercera blanca del carbón (en 1660), la segunda Onza del Azúcar (en 1660), la sisa del Vino de la Bajada de Medidas (en 1663), la sisa de la cuarta blanca del carbón (en 1666), la sisa del Vino del Error de Medidas (en 1667) y la sisa del Cacao y Chocolate (en 1676). De la Hoz (1988), pp. 378-380. 
maravedíes en 1654, en 1679 alcanzaron los 287 millones. Aunque desde 1680 se inició un descenso de la recaudación, debe destacarse que en la última década del siglo su valor superó al de los impuestos municipales y al de las alcabalas, cientos y millones, lo que da una idea de la importancia alcanzada por esta fuente de ingresos.

En el Gráfico 2 se compara la trayectoria de los impuestos reales (millones, alcabalas y cientos) con la de los ingresos percibidos por el ayuntamiento (impuestos municipales y servicios de millones transferidos). Aunque más arriba hemos resaltado las diferencias de origen entre los impuestos municipales (los introducidos para atender los gastos ordinarios de la villa y los establecidos para servir de hipoteca de las sumas servidas a la Monarquía) y los servicios de millones "en empeño", de las que eran bien conscientes los regidores y los contadores madrileños, en la práctica tales diferencias tenían poco relieve, y ambos tipos de ingresos estaban unidos. Buena muestra de ello, que justifica que en el Gráfico 2 se ofrezca la trayectoria del valor conjunto de lo cobrado por el ayuntamiento (por impuestos municipales y por millones en traspaso), se encuentra en el hecho de que, en 1672, casi 60 millones de maravedíes de los impuestos municipales se destinaron a abonar parte de los intereses devengados por los "efectos de villa" situados sobre las Sisas Reales, mientras que años después, en 1685, sucedió lo contrario: parte de lo recaudado por los millones transferidos se empleó en el pago de los intereses devengados por los "efectos" situados sobre los impuestos municipales ${ }^{43}$.

En cuanto a lo recaudado por impuestos reales se perciben tres fases. La inicial, de 1621 a 1640, aparece dominada por un alza acusada. Considerando los datos del Apéndice 1, que suministran información para las dos primeras décadas del siglo, cabe afirmar que el período 1621-1640 debe incluirse dentro de una etapa más amplia, que abarcaría entre 1601 y 1640, durante la cual las percepciones de los tres dacios crecieron de 37 a 377 millones de maravedíes, lo que constituye un fiel reflejo del rápido crecimiento madrileño de las primeras décadas del Seiscientos.

Aunque las recaudaciones descendieron algo después de 1640, el Grafico 2 muestra que en un segundo período, entre 1641 y 1661, los valores de alcabalas, cientos y millones se mantuvieron en niveles todavía elevados y superiores a los de los decenios iniciales (entre 300 y 340 millones de maravedíes anuales). A semejante estabilidad sucedió un notable descenso en la tercera y última fase, entre 1662 y 1700, durante la cual los ingresos cayeron de 336,7 a 179 millones de maravedíes anuales.

En trabajos anteriores hemos mostrado que en el primer lustro de la década de 1680 la Corona concedió abundantes descuentos en las alcabalas, millones y cientos a través del célebre Encabezamiento General del Reino de 1683-1685. Estas 


\section{GRÁFICO 2}

RECAUDACIÓN DE LOS IMPUESTOS REALES Y DE LOS COBRADOS POR MADRID, 1621-1700

(millones de maravedíes corrientes)

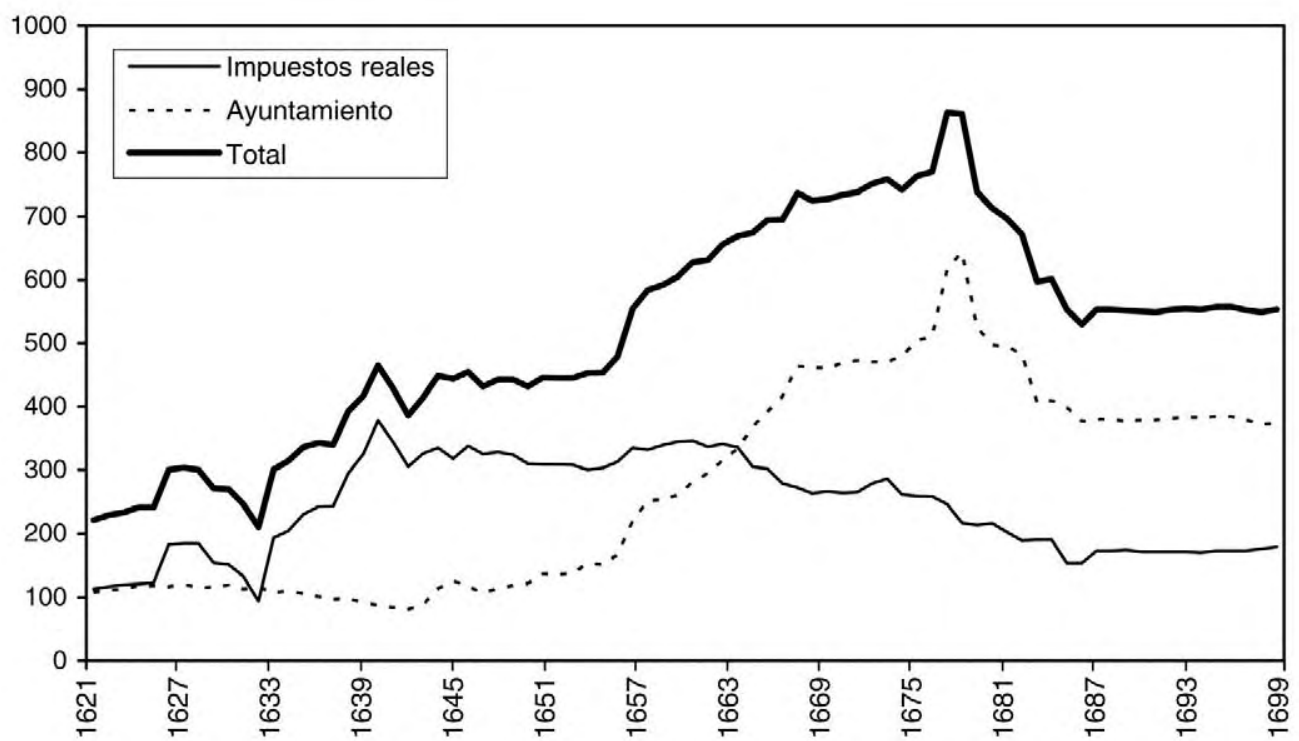

Leyenda: Impuestos reales: millones, alcabalas y cientos.

Ayuntamiento: impuestos municipales y millones en traspaso.

Total: impuestos reales e ingresos controlados por el municipio.

Fuentes: Apéndice 1.

rebajas se añadieron a la desaparición del servicio de quiebras de millones tras 1670 , y se completaron, desde 1686, con la retirada de los servicios de los tres millones y las carnes, y la rebaja a la mitad de los cuatro cientos, provocando un notable descenso de las recaudaciones de estos dacios, que estimamos en un 45 por 100 entre 1680 y $1686^{44}$.

Del Gráfico 2 se desprende que, en el caso de Madrid, la caída de lo recaudado por alcabalas, cientos y millones comenzó antes que en el resto del reino, en 1662, pero no por la desaparición de figuras fiscales o por la concesión de rebajas en los gravámenes, sino por la transferencia de la mayoría de los servicios de millones a la ciudad. 
Por lo demás, el Gráfico 2 también muestra la trayectoria del conjunto de las cantidades pagadas por los madrileños en concepto de millones, alcabalas, cientos, impuestos municipales y millones transferidos entre 1621 y 1700. Si se acepta la representatividad de estos impuestos, esta serie puede dar idea de las principales fases de la evolución de la carga tributaria (municipal y real) en la villa, en términos nominales, en ese período. En la década de 1630 dicha carga experimentó un alza notable, desde 210 millones de maravedíes en 1632 a 465 en 1640, al compás de la elevación de lo satisfecho en concepto de millones. Tras los altos niveles de 1640 se produjo un leve descenso hasta 1654, cuando comenzó una nueva fase, que se prolongaría hasta 1679, en la que la carga tributaria nominal alcanzó los valores máximos de toda la centuria; en su transcurso, superó con holgura la cota de 1640, a resultas del aumento de lo recaudado por impuestos municipales y servicios de millones transferidos. $\mathrm{Y}$ debe subrayarse que este aumento coincidió en gran parte con una fase de estancamiento demográfico tras el agotamiento, en el decenio de 1630, de la etapa expansiva de la villa, lo que no pudo sino agravar sus consecuencias ${ }^{45}$.

Finalmente, en la década de 1680, tuvo lugar un descenso de la carga tributaria nominal. Dado que la caída de las recaudaciones de los impuestos reales venía experimentándose desde 1662, la principal causa de este hecho reside en el descenso de las cantidades cobradas por los impuestos municipales, sobre todo a causa de la retirada de varias sisas municipales y de la concesión de rebajas en los arriendos. En concreto, las sisas y recargos sobre el vino consumido en Madrid estuvieron arrendados por el gremio de herederos de viñas en 343 millones de maravedíes anuales hasta comienzos de 1680, cuando el contrato pasó a manos del gremio de los taberneros por un valor de 314,5 millones. Tras la deflación de principios de año, en abril de 1680 una real orden dispuso que disminuyese la postura del azumbre de vino ordinario de 56 maravedíes a 48, provocando la salida de los taberneros, que retomaron el arriendo en julio por 242,6 millones de maravedíes. Asimismo, también en 1680 se retiraron las cuatro blancas del carbón que valían casi 50 millones. Esto explica el descenso de la carga tributaria nominal de 861 millones de maravedíes en 1679 a 713 en 1681. A continuación, a finales de 1683, el arriendo de las sisas y gravámenes sobre el vino se redujo de nuevo a 171 millones de maravedíes y, por último, en 1686 los cuatro unos por ciento se rebajaron a la mitad. Tras estos descuentos, la carga tributaria nominal cayó hasta cerca de 550 millones de maravedíes anuales en los últimos años de la centuria, si bien debe subrayarse que estos niveles rebasaban con holgura los del período inicial ${ }^{46}$.

\footnotetext{
$45 \quad$ Carbajo (1987), p. 227.

46 AVM, Secretaría, 3-492-25, y Archivo Histórico Nacional (AHN, en adelante), Consejos, legajo 10.108 y libro 3.467 .
} 


\section{La trayectoria de la carga tributaria en Madrid}

El cálculo de la presión fiscal, entendida como el cociente entre la carga tributaria y el PIB, es uno de los métodos más usados para estudiar el impacto de la fiscalidad sobre las economías actuales. Sin embargo, las limitaciones de nuestras fuentes dificultan la estimación de este indicador para las economías preindustriales ${ }^{47}$. Por ello, hemos optado por deflactar el valor nominal de la carga tributaria en Madrid (alcabalas, millones, cientos, impuestos municipales y millones en traspaso) entre 1621 y 1700 por el índice de precios en Castilla la Nueva de P. Martín Aceña ${ }^{48}$, lo que permite presentar la evolución de dicha carga en términos reales ${ }^{49}$.

En el Gráfico 3 se aprecia que la carga tributaria real conoció un marcado ascenso entre 1621 y 1700 , pudiéndose distinguir varias fases. Tras la estabilidad del lapso 1621-1635, entre 1636 y 1680 discurrió una larga etapa de alza de aquélla, destacando en su seno las subidas de 1636-1640 (en que la carga tributaria real creció un 42 por 100 respecto del quinquenio precedente) y 1656-1660 (con un alza del 29 por 100), debidas ambas a la introducción de nuevos tributos, así como la de 1671-1675, cuya causa residió, sobre todo, en el descenso de los precios $^{50}$.

Lo ocurrido en 1671-1675 nos recuerda que la trayectoria de la carga tributaria real no sólo dependió de las recaudaciones, sino que también estuvo influida por las oscilaciones de los precios, algo bien visible entre 1661-1670 y 1676-1680. En estos períodos (y en 1671-1675) la carga tributaria nominal alcanzó los mayores valores del siglo, pero al mismo tiempo los precios también se situaron en las cotas más elevadas debido a la inflación impulsada por las alteraciones del vellón, lo que contribuyó a amortiguar la subida de la carga tributaria real causando, incluso, el descenso que recoge el gráfico. Con todo, debe subrayarse que, en estos años, la carga tributaria real todavía se situó en niveles muy superiores a los del período $1621-1635^{51}$.

Si hasta 1680 la inflación del vellón contribuyó a aminorar en varias ocasiones el alza de la carga tributaria real, tras las medidas deflacionistas de ese año sucedió todo lo contrario: al caer los precios más que la carga tributaria nominal, la carga tributaria en términos reales tendió a subir. Como resultado, desde 1681 arrancó la

\footnotetext{
47 Sobre tales dificultades, véase Fernández de Pinedo (1997), p. 66, y Bilbao (1990), pp. 38-41.

48 Martín Aceña (1992), p. 364.

49 García Sanz (1991), p. 16.

50 En 1636-1640 se implantaron varios recargos monetarios sobre el vino de los 24 millones. También se introdujeron los servicios de las quiebras de millones y de los 8.000 soldados (en 1638), junto con el primer ciento (en 1639). Por su parte, en 1637, el municipio introdujo la sisa del Vino de la Salud. A su vez, en 1656-1660 aparecieron nuevos servicios de millones (la sisa moderada de las carnes y el servicio de los tres millones) y varios impuestos municipales, como la sisa del carnero de Quiebras, la sisa de la Vaca de Hospitales, la sisa del Vino de Olivenza, la tercera blanca del carbón y la segunda onza del azúcar (De la Hoz, 1988, pp. 379-381). 


\section{GRÁFICO 3}

EVOLUCIÓN DE LA CARGA TRIBUTARIA REAL EN MADRID, 1621-1700

(millones de maravedíes constantes)

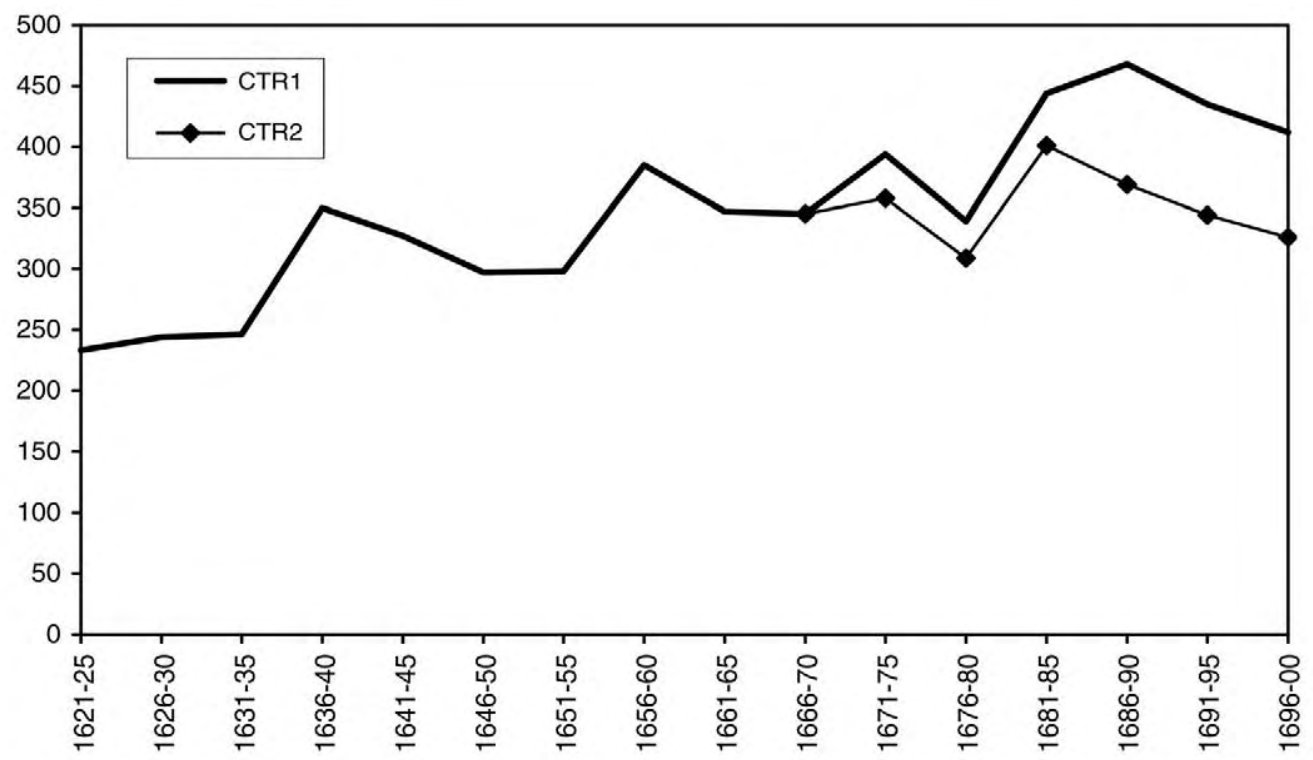

Leyenda: CTR1: Carga tributaria real.

CTR2: Carga tributaria real sin las quiebras desde 1670 y sin las carnes y los tres millones desde 1686.

Fuentes: Para las recaudaciones, Apéndice 1. Para los precios, Martín Aceña (1992), p. 364.

tercera y última fase, caracterizada por un nuevo y destacado aumento de la carga tributaria real, alcanzando ésta las cotas más elevadas del período $1621-1700^{52}$.

El alza de la carga tributaria real tras la deflación de 1680 constituye un hecho bien constatado en otras regiones ${ }^{53}$. Para aminorar dicho ascenso, la Corona, que ya había retirado el servicio de las quiebras de millones en 1670, introdujo el Encabezamiento General del Reino de Millones, Alcabalas y Cientos entre 1683 y 1685, y en 1686 rebajó los cuatro unos por ciento a la mitad, suprimiendo además los servicios de las carnes y los tres millones ${ }^{54}$. Aunque al amparo del Encabezamiento General el valor de los millones, alcabalas y cientos se redujo casi un 25 por 100 en todo el reino (Apéndice 2), en Madrid este porcentaje fue muy inferior (7 por 100). A esto se añade

En concreto, el valor medio anual de las recaudaciones de los impuestos reales, municipales y millones transferidos en el quinquenio 1681-1685 fue un 18 por 100 inferior al de 1676-1680, mientras que en el mismo período los precios cayeron un 37,5 por 100 .

53 Como en Cantabria, véase Lanza (2005), p. 54.

54 Sobre estas medidas, véase Sánchez Belén (1996), pp. 225-247 y Andrés Ucendo (2001), pp. 605-614. 
que la villa mantuvo las quiebras tras 1670 y los tres millones y las carnes tras 1686 . Según nuestros cálculos, las quiebras representaban el 9 por 100 del valor de lo ingresado por millones, cientos, alcabalas, impuestos municipales y millones en traspaso, mientras que los tres millones y las carnes suponían el 11 por 100. De haberse retirado estos tres servicios, la carga tributaria real hubiera sido muy inferior desde 1671 y, en especial, desde 1686, y el marcado ascenso de la misma en las dos últimas décadas del siglo, reflejado en el Gráfico 3, no se hubiera producido.

Para completar el análisis, debe comprobarse si al ascenso en la carga tributaria real correspondió una subida de ésta en términos per capita. Al respecto, el Cuadro 2 recoge la estimación de la carga tributaria real en términos per capita en cuatro fechas para las que disponemos de buenos datos acerca del tamaño de la población madrileña ${ }^{55}$.

El Cuadro 2 sugiere que durante el período 1621-1700 la carga tributaria real también creció en términos per capita, siendo reseñable, de nuevo, el alza de 1683 y de 1695, fruto del mantenimiento de las quiebras, los tres millones y las carnes, lo que avala los resultados del Gráfico 3. Como se desprende del cuadro, de haberse suprimido estos servicios el aumento de la carga tributaria real por habitante en los años finales del siglo hubiese sido inferior, y en 1695 se habría situado en niveles similares a los de 1654 .

Dado que la conservación de las quiebras, los tres millones y las carnes estuvo dictada, según quedó dicho, por la necesidad de pagar a los "efectistas" sus intereses, puede afirmarse que, debido al desarrollo de estrechas conexiones entre la fiscalidad y las finanzas madrileñas, y las de la Monarquía entre 1653 y 1678, la villa no se benefició demasiado de la política de alivio fiscal adoptada por la Corona en las décadas finales del siglo. Si se recuerda que, como también se ha indicado, los impuestos recaudados en la capital eran esencialmente indirectos y repercutían en el precio de productos como el vino, la carne y el aceite, cabe interrogarse acerca de en qué medida el marcado incremento de la carga tributaria real entre 1681 y 1700 pudo afectar a la dieta de los madrileños de la época. A su vez, ello incita a suscitar la cuestión del grado de influencia de esta escalada de la carga tributaria real en la gestación y el estallido del "motín de los gatos" de $1699^{56}$.

55 Según Carbajo (1987), p. 227, la ciudad de Madrid rebasó en 1630 los 130.000 habitantes, cifra que se ha asignado en el Cuadro 2 a 1629. Tras la crisis de 1630-1631, la población de la ciudad se estancó en torno a 125.000 habitantes, cantidad que hemos asignado al año 1654. En 1670 se inició una moderada expansión, aumentando la población hasta 1696 y rebasando el límite de 1630. Considerando esta evolución, nos ha parecido prudente estimar en 127.500 el número de habitantes de la villa en 1683 y en 130.000, de nuevo, en 1695.

56 Debe tenerse en cuenta, además, que el alza de la carga tributaria en términos reales no debió de afectar por igual a todos los sectores de la sociedad madrileña. Prácticas como las refacciones a eclesiásticos, la concesión de franquicias a los embajadores y el desarrollo de despensas de particulares, hacen suponer que el peso de la creciente carga tributaria hubo de distribuirse de modo muy desigual, perjudicando a los sectores populares de la villa en beneficio de los privilegiados. Sobre este asunto, véase López García (1998), pp. 320-321. Respecto al "motín de los gatos", Nieto y González (2001), pp. 377-400. 


\section{CUADRO 2}

LA CARGA TRIBUTARIA REAL Y NOMINAL PER CAPITA EN MADRID EN 1629, 1654, 1683 Y 1696

(maravedíes corrientes y constantes, y números índice, base $100=1629$ )

\begin{tabular}{lccccccc}
\hline Año & Población & $\begin{array}{c}\text { Carga nominal } \\
\text { per capita }\end{array}$ & $\begin{array}{c}\text { Índice de } \\
\text { precios }\end{array}$ & $\begin{array}{c}\text { Carga real } \\
\text { per capita (a) }\end{array}$ & $\begin{array}{c}\text { Índice } \\
\text { (a) }\end{array}$ & $\begin{array}{c}\text { Carga real } \\
\text { per capita (b) }\end{array}$ & $\begin{array}{c}\text { Índice } \\
\text { (b) }\end{array}$ \\
\hline $\mathbf{1 6 2 9}$ & 130.000 & $2.081,5$ & 100,0 & $2.081,5$ & 100,0 & $2.081,5$ & 100,0 \\
$\mathbf{1 6 5 4}$ & 125.000 & $3.623,0$ & 122,0 & $2.970,0$ & 142,6 & $2.970,0$ & 142,6 \\
$\mathbf{1 6 8 3}$ & 127.500 & $5.267,0$ & 129,5 & $4.067,0$ & 195,3 & $3.690,0$ & 177,0 \\
$\mathbf{1 6 9 5}$ & 130.000 & $4.255,0$ & 108,0 & $3.940,0$ & 189,2 & $3.110,0$ & 149,0 \\
\hline
\end{tabular}

* Carga real per capita (a): la carga tributaria incluye las quiebras tras 1670 y los tres millones y las carnes tras 1686.

** Carga real per capita (b): la carga tributaria no incluye las quiebras tras 1670 , ni los tres millones y las carnes tras 1686.

Fuentes: Para los datos recaudatorios, Apéndice 1. Para los precios, Martín Aceña (1992), p. 364.

\section{Conclusiones}

El análisis efectuado en las páginas anteriores permite apuntar algunos elementos acerca del papel de Madrid en la fiscalidad castellana del Seiscientos. Los principales ingresos municipales y regios se recaudaban mediante impuestos indirectos sobre el consumo de productos de primera necesidad, entre los que destacaba el vino y la carne. Si atendemos a la trayectoria de las recaudaciones de las alcabalas, cientos y servicios de millones, se observa que aquéllas crecieron de modo notable hasta 1661. En 1662 comenzó un descenso, cuya causa principal se halla en el traspaso a la capital de la mayor parte de los servicios de millones, lo que nos permite evaluar el cambiante papel de Madrid en la fiscalidad castellana del siglo XVII. En la primera mitad de la centuria la villa había sido la capital de un distrito de creciente importancia para la Real Hacienda, pero tras la transferencia de la mayor parte de los servicios de millones a la ciudad después de 1653, dicha importancia se redujo, si bien a cambio creció la relevancia de Madrid como fuente de cuantiosos servicios para la Corona.

El Gráfico 2 muestra que la carga tributaria nominal creció en el transcurso del siglo. Deflactando ésta con el índice de precios de Castilla la Nueva, se comprueba que la carga tributaria real también aumentó durante el Seiscientos, siendo reseñables las alzas de las décadas centrales y, en especial, los altos niveles alcanzados 
luego de 1681. Cuando recordamos que lo anterior fue el resultado de la conservación de los servicios de quiebras de millones, tras 1670, y las carnes y los tres millones, tras 1686, debido a la necesidad de pagar sus intereses a los "efectistas, puede afirmarse que las estrechas conexiones entre las finanzas madrileñas y las de la Monarquía impidieron que la capital se beneficiara de la política de alivio fiscal emprendida en las últimas décadas del siglo XVII.

\section{Bibliografía}

ANDRÉS UCENDO, José Ignacio (1999): La fiscalidad en Castilla en el siglo XVII: los servicios de millones, 1601-1700, Lejona, Universidad del País Vasco.

-(2001): "Castile's Fiscal System in the Seventeenth Century", The Journal of European Economic History, 30, pp. 597-621.

ARTOLA, Miguel (1982): La Hacienda del Antiguo Régimen, Madrid, Alianza.

BILBAO BILBAO, Luis María (1990): “Ensayo de reconstrucción histórica de la presión fiscal en Castilla durante el siglo XVI", en FERNÁNDEZ DE PINEDO, Emiliano (ed.), Haciendas forales y Hacienda Real. Homenaje a D. Miguel Artola y D. Felipe Ruiz Martín, Bilbao, Universidad del País Vasco, pp. 37-62.

CAPELLA, Miguel, y MATILLA TASCÓN, Antonio (1957): Los Cinco Gremios Mayores de Madrid. Estudio Crítico Histórico, Madrid.

CARBAJO ISLA, María (1987): La población de la villa de Madrid desde finales del siglo XVI hasta mediados del siglo XIX, Madrid, Siglo XXI.

CÁRCELES DE GEA, Beatriz (2000): Fraude y desobediencia fiscal en la Corona de Castilla, 1621-1700, Salamanca, Junta de Castilla y León.

DE BERNARDO, José Manuel (1993): Corrupción política y centralización administrativa. La Hacienda de Propios en la Córdoba de Carlos II, Córdoba, Universidad de Córdoba.

DE LA HOZ GARCíA, Carlos (1988): “El sistema fiscal de Madrid en el Antiguo Régimen: las sisas", Anales del Instituto de Estudios Madrileños, XXV, pp. 371-386.

-(1989): "Hacienda, deuda municipal y poder urbano en el Madrid del siglo XVII", Comunicación presentada al IV Congreso de la Asociación Española de Historia Económica, Alicante.

DOMÍNGUEZ ORTIZ, Antonio (1960): Política y Hacienda de Felipe IV, Madrid, Editorial de Derecho Financiero.

FERNÁNDEZ DE PINEDO, Emiliano (1993): “Fiscalidad y Absolutismo en Castilla en la primera mitad del siglo XVII", en CREMADES, María del Carmen, y FORTEA, José Ignacio (eds.), Actas de la II Reunión Científica de la Asociación Española de Historia Moderna, Murcia, Universidad de Murcia, pp. 33-51. 
-(1997): “La participación fiscal catalana en la Monarquía Hispánica (1599-1640)", Manuscrits, 15, pp. 65-96.

FORTEA PÉREZ, José Ignacio (2000): “Los donativos en la política fiscal de los Austrias, (1625-1637)", en RIBOT, Luis Antonio, y DA ROSA, Luigi (eds.), Pensamiento y política fiscal económica en la Época Moderna, Madrid, Actas, pp. 31-76.

GARCÍA CANO, María Isabel (2003): La Córdoba de Felipe II. Gestión financiera de un patrimonio municipal e intervención política de una monarquía supranacional, Córdoba, Universidad de Córdoba.

GARCÍA DE PASO, José Isidoro (2000): “La estabilización monetaria en Castilla bajo Carlos II", Revista de Historia Económica, XVIII, 1, pp. 49-77.

GARCÍA GARCÍA, Carmen (1996): La crisis de las haciendas locales. De la reforma administrativa a la reforma fiscal (1743-1835), Salamanca, Junta de Castilla y León.

GARCÍA SANZ, Ángel (1991): "Repercusiones de la fiscalidad sobre la economía castellana en los siglos XVI y XVII", Hacienda Pública Española, I, pp. 15-24.

GELABERT, Juan Eloy (1997): La bolsa del Rey. Rey, reino y fisco en Castilla, 1598-1648, Barcelona, Crítica.

GUTIÉRREZ ALONSO, Adriano (1989): Estudio sobre la decadencia de Castilla. La ciudad de Valladolid en el siglo XVII, Valladolid, Universidad de Valladolid.

HERNÁNDEZ, Mauro (1995): A la sombra de la Corona. Poder local y oligarquía urbana, Madrid, 1606-1808, Madrid, Siglo XXI.

LANZA GARCÍA, Ramón (2005): “Fiscalidad real en Cantabria: alcabalas, cientos y millones en la época de los Austrias", Investigaciones de Historia Económica, 3, pp. 43-72.

LÓPEZ GARCÍA, José Miguel (dir.) (1998): El impacto de la Corte en Castilla. Madrid y su territorio en la época moderna, Madrid, Siglo XXI.

LÓPEZ NEVOT, José Antonio (1995): “La hacienda municipal de Granada (14921600)", Anuario de Historia del Derecho Español, 65, pp. 749-805.

MARCOS MARTÍN, Alberto (2003): “Enajenaciones por precio del patrimonio regio en los siglos XVI y XVII. Balance historiográfico y perspectivas de análisis", en VI Coloquio de Metodología Histórica Aplicada. Balance de la historiografía modernista, 1973-2001, Santiago.

-(2004): "Ventas de rentas reales en Castilla en los siglos XVI y XVII. Algunas consideraciones en torno a su volumen y cronología", en GARCÍA FERNÁNDEZ, Máximo, y SOBALER SECO, María Ángeles (coords.), Estudios en homenaje al profesor Teófanes Egido, Valladolid, Junta de Castilla y León, pp. 265-297.

MARTÍN ACEÑA, Pablo (1992): "Los precios en Europa durante los siglos XVI y XVII. Estudio comparativo", Revista de Historia Económica, 3, pp. 359-395.

MARTÍNEZ RUIZ, José Ignacio (1992): Finanzas municipales y crédito público en la España Moderna. La hacienda de la ciudad de Sevilla, 1528-1768, Sevilla, Ayuntamiento de Sevilla. 
MONTURIOL GONZÁLEZ, María de los Ángeles (1985): “El ingreso en la Hacienda Municipal de Madrid: su estructura y su evolución, (1464-1497)", en SÁEZ, Emilio, SEGURA, Cristina, y CANTERA, Margarita (coords.), La ciudad hispánica durante los siglos XIII al XVI, Tomo 2, Madrid, Universidad Complutense, pp. 1.027-1.057.

MUGARTEGUI EGUÍA, Isabel (1993): Estado, provincia y municipio. Estructura y coyuntura de las haciendas municipales vascas. Una visión a largo plazo, 1580-1900, Oñate, IVAP.

NIETO SÁNCHEZ, José Antonio, y GONZÁLEZ PAÑERO, Juan Antonio (2001): “El conflicto social en el Madrid del siglo XVII", en GUILLAMÓN ÁLVAREZ, Francisco Javier, y RUIZ IBÁÑEZ, José Javier (eds.), Lo conflictivo y lo consensual en Castilla. Sociedad y poder político, 1521-1715, Murcia, Universidad de Murcia, pp. 377-400.

PEÑASCO DE LA FUENTE, Hilario (1891): Las sisas de Madrid, Madrid, Imprenta de Enrique Rubiños.

PULIDO BUENO, Ildefonso (1996): La Real Hacienda de Felipe III, Huelva, Artes Gráficas Andaluzas.

QUINTANA TORET, Francisco José (1989): "Endeudamiento municipal, mercado financiero y tesoros en Andalucía. Los censualistas del concejo malagueño", Archivo Hispalense, 219, pp. 81-106.

REY CASTELAO, Ofelia (2004): “Los estudios sobre fiscalidad en la época moderna: ¿fenómeno historiográfico real o aparente?", Obradoiro de Historia Moderna, 13, pp. 215-252.

RUIZ MARTÍN, Felipe (1978): “Procedimientos crediticios para la recaudación de los tributos fiscales en las ciudades castellanas durante los siglos XVI y XVII: el caso de Valladolid", en OTAZU, Alfonso (ed.), Dinero y Crédito. Primer Coloquio Internacional de Historia Económica, Madrid, Moneda y Crédito, pp. 37-47.

SAAVEDRA, Pegerto (1993): A facenda real na Galica do Antigo Rexime, Santiago de Compostela, Universidad de Santiago.

SÁNCHEZ BELÉN, Juan Antonio (1996): La politica fiscal en Castilla durante el reinado de Carlos II, Madrid, Siglo XXI.

SEBASTIÁN, Mercedes, y VELA, José (1993): “Hacienda Real y presión fiscal en Castilla a comienzos del reinado de Felipe IV", en FORTEA, José Ignacio, y CREMADES, María del Carmen (eds.), Política y Hacienda en el Antiguo Régimen, Murcia, Universidad de Murcia, pp. 553-567. 


\section{APÉNDICE 1}

VALOR DE LAS ALCABALAS, CIENTOS, MILLONES, MILLONES TRANSFERIDOS

E IMPUESTOS MUNICIPALES EN MADRID, 1601-1700

(millones de maravedíes corrientes)

\begin{tabular}{|c|c|c|c|c|c|c|c|c|}
\hline Años & (1) & (2) & (3) & $(4)=(1)+(2)+(3)$ & (5) & (6) & $(7)=(5)+(6)$ & $(8)=(4)+(7)$ \\
\hline 1601 & 21,2 & & 15,6 & 36,8 & & & & \\
\hline 1602 & 21,2 & & 15,7 & 36,9 & & & & \\
\hline 1603 & 21,2 & & 25,3 & 46,5 & & & & \\
\hline 1604 & 21,2 & & 28,2 & 49,4 & & & & \\
\hline 1605 & 19,2 & & 24,3 & 43,5 & & & & \\
\hline 1606 & 17,3 & & 46,3 & 63,6 & & & & \\
\hline 1607 & 21,3 & & 56,0 & 77,3 & & & & \\
\hline 1608 & 30,6 & & 56,4 & 87,0 & & & & \\
\hline 1609 & 30,6 & & 60,8 & 91,4 & & & & \\
\hline 1610 & 30,6 & & 60,8 & 91,4 & & & & \\
\hline 1611 & 41,6 & & 62,8 & 104,4 & & & & \\
\hline 1612 & 40,6 & & 68,7 & 109,3 & & & & \\
\hline 1613 & 40,6 & & 69,1 & 109,7 & & & & \\
\hline 1614 & 41,5 & & 80,0 & 121,5 & & & & \\
\hline 1615 & 43,7 & & 46,8 & 90,5 & & & & \\
\hline 1616 & 45,8 & & 54,3 & 100,1 & & & & \\
\hline 1617 & 45,8 & & 53,2 & 99,0 & & & & \\
\hline 1618 & 45,8 & & 52,4 & 98,2 & & & & \\
\hline 1619 & 45,8 & & 42,2 & 88,0 & & & & \\
\hline 1620 & 48,1 & & 71,2 & 119,3 & & & & \\
\hline 1621 & 47,1 & & 65,7 & 112,8 & & 108,2 & 108,2 & 221,0 \\
\hline 1622 & 47,1 & & 69,7 & 116,8 & & 112,3 & 112,3 & 229,1 \\
\hline 1623 & 47,1 & & 72,5 & 119,6 & & 113,5 & 113,5 & 233,1 \\
\hline 1624 & 47,1 & & 74,2 & 121,3 & & 119,5 & 119,5 & 240,8 \\
\hline 1625 & 46,1 & & 76,9 & 123,0 & & 118,2 & 118,2 & 241,2 \\
\hline 1626 & 76,3 & & 106,4 & 182,7 & & 116,9 & 116,9 & 299,6 \\
\hline 1627 & 76,5 & & 108,0 & 184,5 & & 119,8 & 119,8 & 304,3 \\
\hline 1628 & 76,5 & & 108,0 & 184,5 & & 115,6 & 115,6 & 300,1 \\
\hline 1629 & 76,5 & & 77,5 & 154,0 & & 116,6 & 116,6 & 270,6 \\
\hline 1630 & 76,8 & & 74,2 & 151,0 & & 119,4 & 119,4 & 270,4 \\
\hline
\end{tabular}


APÉNDICE 1 (continuación)

VALOR DE LAS ALCABALAS, CIENTOS, MILLONES, MILLONES TRANSFERIDOS

E IMPUESTOS MUNICIPALES EN MADRID, 1601-1700

(millones de maravedíes corrientes)

\begin{tabular}{|c|c|c|c|c|c|c|c|c|}
\hline Años & (1) & (2) & (3) & $(4)=(1)+(2)+(3)$ & (5) & (6) & $(7)=(5)+(6)$ & $(8)=(4)+(7)$ \\
\hline 1631 & 76,8 & & 56,2 & 133,0 & & 113,0 & 113,0 & 246,0 \\
\hline 1632 & 76,8 & & 17,5 & 94,3 & & 115,8 & 115,8 & 210,1 \\
\hline 1633 & 76,8 & & 116,0 & 192,8 & & 108,0 & 108,0 & 300,8 \\
\hline 1634 & 86,4 & & 118,0 & 204,4 & & 110,0 & 110,0 & 314,4 \\
\hline 1635 & 86,5 & & 143,5 & 230,1 & & 106,0 & 106,0 & 336,1 \\
\hline 1636 & 86,7 & & 155,7 & 242,3 & & 101,0 & 101,0 & 343,3 \\
\hline 1637 & 86,7 & & 156,7 & 243,3 & & 97,0 & 97,0 & 340,3 \\
\hline 1638 & 86,7 & & 208,0 & 294,8 & & 98,0 & 98,0 & 392,8 \\
\hline 1639 & 86,7 & 21,0 & 217,4 & 325,1 & & 92,0 & 92,0 & 417,1 \\
\hline 1640 & 87,0 & 21,0 & 269,6 & 377,6 & & 87,0 & 87,0 & 464,6 \\
\hline 1641 & 86,9 & 21,0 & 236,6 & 344,5 & & 84,0 & 84,0 & 428,5 \\
\hline 1642 & 86,8 & 42,0 & 176,5 & 305,3 & & 81,0 & 81,0 & 386,3 \\
\hline 1643 & 87,6 & 42,0 & 196,9 & 326,5 & & 88,0 & 88,0 & 414,5 \\
\hline 1644 & 87,6 & 42,0 & 205,4 & 335,0 & & 114,0 & 114,0 & 449,0 \\
\hline 1645 & 88,4 & 42,0 & 187,4 & 317,8 & & 126,0 & 126,0 & 443,8 \\
\hline 1646 & 87,9 & 42,0 & 207,8 & 337,7 & & 117,3 & 117,3 & 455,0 \\
\hline 1647 & 87,9 & 42,0 & 194,9 & 324,8 & & 107,5 & 107,5 & 432,3 \\
\hline 1648 & 87,9 & 44,8 & 196,0 & 328,7 & & 114,3 & 114,3 & 443,0 \\
\hline 1649 & 87,9 & 43,1 & 192,7 & 323,7 & & 119,1 & 119,1 & 442,8 \\
\hline 1650 & 87,5 & 44,2 & 178,3 & 310,0 & & 122,0 & 122,0 & 432,0 \\
\hline 1651 & 86,2 & 44,7 & 178,0 & 308,9 & & 136,6 & 136,6 & 445,5 \\
\hline 1652 & 86,1 & 44,6 & 178,0 & 308,7 & & 136,4 & 136,4 & 445,1 \\
\hline 1653 & 86,1 & 44,6 & 177,2 & 307,9 & & 136,9 & 136,9 & 444,8 \\
\hline 1654 & 86,1 & 44,0 & 170,2 & 300,3 & 13,9 & 138,7 & 152,6 & 452,9 \\
\hline 1655 & 86,1 & 44,4 & 173,0 & 303,5 & 14,5 & 136,3 & 151,0 & 454,3 \\
\hline 1656 & 85,9 & 44,7 & 182,0 & 312,6 & 16,1 & 150,0 & 166,0 & 478,7 \\
\hline 1657 & 85,9 & 64,9 & 184,3 & 335,1 & 59,1 & 160,0 & 219,0 & 554,0 \\
\hline 1658 & 85,9 & 64,9 & 181,2 & 332,0 & 83,2 & 169,0 & 252,0 & 584,2 \\
\hline 1659 & 85,9 & 65,0 & 188,2 & 339,1 & 83,0 & 170,0 & 253,0 & 592,0 \\
\hline 1660 & 85,8 & 65,7 & 193,0 & 344,5 & 84,1 & 176,5 & 260,6 & 605,1 \\
\hline 1661 & 85,8 & 65,7 & 195,0 & 346,5 & 88,4 & 193,0 & 281,4 & 627,7 \\
\hline
\end{tabular}




\section{APÉNDICE 1 (continuación)}

VALOR DE LAS ALCABALAS, CIENTOS, MILLONES, MILLONES TRANSFERIDOS

E IMPUESTOS MUNICIPALES EN MADRID, 1601-1700

(millones de maravedíes corrientes)

\begin{tabular}{|c|c|c|c|c|c|c|c|c|}
\hline Años & (1) & (2) & (3) & $(4)=(1)+(2)+(3)$ & (5) & (6) & $(7)=(5)+(6)$ & $(8)=(4)+(7)$ \\
\hline 1662 & 85,8 & 66,3 & 184,6 & 336,7 & 103,4 & 191,0 & 294,4 & 631,1 \\
\hline 1663 & 85,8 & 66,3 & 188,7 & 340,8 & 105,0 & 209,8 & 314,8 & 655,6 \\
\hline 1664 & 85,8 & 66,3 & 184,0 & 336,1 & 106,4 & 226,7 & 333,1 & 669,2 \\
\hline 1665 & 85,8 & 74,0 & 145,5 & 305,3 & 141,0 & 227,5 & 368,5 & 673,8 \\
\hline 1666 & 85,7 & 89,5 & 126,8 & 302,0 & 159,0 & 233,0 & 392,0 & 694,0 \\
\hline 1667 & 85,7 & 88,2 & 105,0 & 278,9 & 173,0 & 243,0 & 416,0 & 695,0 \\
\hline 1668 & 85,7 & 88,5 & 97,6 & 271,8 & 192,0 & 272,0 & 464,0 & 735,8 \\
\hline 1669 & 85,7 & 88,5 & 88,4 & 262,6 & 192,0 & 270,0 & 462,0 & 724,6 \\
\hline 1670 & 85,6 & 91,0 & 88,9 & 265,5 & 193,3 & 268,0 & 461,3 & 727,0 \\
\hline 1671 & 85,4 & 90,0 & 89,0 & 264,4 & 193,1 & 276,0 & 469,0 & 733,5 \\
\hline 1672 & 85,4 & 90,5 & 88,8 & 264,7 & 193,6 & 279,0 & 472,6 & 737,3 \\
\hline 1673 & 85,4 & 90,3 & 103,5 & 279,2 & 193,4 & 278,0 & 471,4 & 750,6 \\
\hline 1674 & 85,4 & 89,7 & 111,4 & 286,5 & 193,4 & 278,0 & 471,4 & 758,1 \\
\hline 1675 & 85,3 & 89,5 & 86,6 & 261,4 & 197,4 & 282,0 & 479,4 & 741,0 \\
\hline 1676 & 84,4 & 89,5 & 84,8 & 258,7 & 202,4 & 302,0 & 504,4 & 763,1 \\
\hline 1677 & 84,2 & 89,5 & 84,4 & 258,1 & 204,4 & 307,0 & 511,4 & 769,5 \\
\hline 1678 & 84,2 & 84,4 & 77,1 & 245,7 & 248,5 & 369,0 & 617,5 & 863,2 \\
\hline 1679 & 84,2 & 84,4 & 48,7 & 217,3 & 287,0 & 357,0 & 644,0 & 861,3 \\
\hline 1680 & 83,1 & 84,4 & 45,4 & 213,0 & 251,2 & 274,0 & 525,2 & 738,2 \\
\hline 1681 & 83,6 & 84,4 & 47,6 & 215,6 & 247,2 & 250,0 & 497,2 & 712,8 \\
\hline 1682 & 83,6 & 70,6 & 48,2 & 202,4 & 247,2 & 247,0 & 494,0 & 696,6 \\
\hline 1683 & 72,0 & 69,8 & 46,7 & 188,5 & 236,0 & 247,0 & 483,0 & 671,5 \\
\hline 1684 & 72,0 & 71,2 & 46,8 & 190,0 & 199,5 & 208,0 & 407,5 & 597,5 \\
\hline 1685 & 72,0 & 71,6 & 46,8 & 190,4 & 198,5 & 212,0 & 410,5 & 601,0 \\
\hline 1686 & 72,0 & 34,7 & 46,8 & 153,5 & 196,5 & 203,0 & 399,5 & 553,0 \\
\hline 1687 & 72,0 & 34,7 & 46,8 & 153,5 & 186,4 & 190,5 & 377,0 & 530,4 \\
\hline 1688 & 85,1 & 41,0 & 46,8 & 173,0 & 187,7 & 192,6 & 380,3 & 553,3 \\
\hline 1689 & 85,1 & 40,7 & 46,8 & 172,6 & 187,4 & 192,6 & 380,0 & 552,6 \\
\hline 1690 & 85,1 & 42,0 & 46,8 & 173,9 & 187,6 & 189,4 & 377,0 & 550,9 \\
\hline 1691 & 84,5 & 42,2 & 44,6 & 171,3 & 189,3 & 189,4 & 378,7 & 550,0 \\
\hline 1692 & 84,5 & 41,6 & 44,6 & 170,7 & 190,8 & 187,8 & 378,6 & 549,3 \\
\hline
\end{tabular}


APÉNDICE 1 (continuación)

VALOR DE LAS ALCABALAS, CIENTOS, MILLONES, MILLONES TRANSFERIDOS

E IMPUESTOS MUNICIPALES EN MADRID, 1601-1700

(millones de maravedíes corrientes)

\begin{tabular}{|c|c|c|c|c|c|c|c|c|}
\hline Años & (1) & (2) & (3) & $(4)=(1)+(2)+(3)$ & (5) & (6) & $(7)=(5)+(6)$ & $(8)=(4)+(7)$ \\
\hline 1693 & 84,5 & 41,6 & 44,6 & 170,7 & 192,8 & 189,2 & 382,0 & 552,7 \\
\hline 1694 & 84,5 & 41,6 & 44,6 & 170,7 & 194,5 & 188,5 & 383,0 & 553,7 \\
\hline 1695 & 83,9 & 41,6 & 44,6 & 170,1 & 194,5 & 188,5 & 383,0 & 553,1 \\
\hline 1696 & 86,3 & 41,6 & 45,1 & 173,0 & 194,0 & 190,5 & 384,5 & 557,5 \\
\hline 1697 & 86,3 & 41,2 & 45,1 & 172,6 & 193,7 & 190,5 & 384,2 & 556,8 \\
\hline 1698 & 86,3 & 41,2 & 45,1 & 172,6 & 191,9 & 187,5 & 379,0 & 552,0 \\
\hline 1699 & 86,3 & 44,7 & 45,1 & 176,1 & 189,0 & 183,5 & 372,5 & 548,6 \\
\hline 1700 & 88,7 & 44,8 & 45,1 & 178,6 & 189,0 & 185,5 & 374,5 & 553,1 \\
\hline
\end{tabular}

(1) Alcabalas.

(2) Cientos.

(3) Millones.

(4) $=(1)+(2)+(3)$ Impuestos reales.

(5) Millones transferidos.

(6) Impuestos municipales.

$(7)=(5)+(6)$ Cantidades recaudadas por Madrid.

$(8)=(4)+(7)$ Total.

Fuentes: Para las alcabalas, AGS, Contadurías Generales, legajos 945-964, 971, 975, 976, 980, 997, 1.002, 1.003, $1.009,1.016,1.022,1.027,1.032,1.036,1.037,1.039,1.042,1.043,1.047,1.052,1.057,2.420,2.423,2.424,2.429$, 2.431; Dirección General del Tesoro, Inventario 4, legajos 420, 425-428 y 431-434, e Inventario 24, legajo 629. Para los cientos de Madrid, AGS, Contadurías Generales, legajos 1.260-1.298. Para los millones de Madrid, Andrés Ucendo (1999), pp. 202-204. Para las sisas reales y municipales, AVM, Secretaría, legajos 3-259-2, 3-237-2, 3-244-1, 3-259-1, 4-321-5, 3-242-2, 3-245-1, 3-245-2, 3-239-1, 2-238-2, 3-239-2, 3-240-1, 3-237-3, 3-241-1, 3-241-2, 3-246-1, 3-241-3, 3249-1, 3-240-2, 3-249-2, 3-251-1, 3-243-1, 3-243-2, 3-253-1, 3-243-3, 3-247-1, 3-255-1, 3-280-6, 3-256-1, 3-259-1, 3254-1, 3-256-2, 3-261-1, 3-261-2, 3-261-6, 3-262-1, 3-262-2, 3-262-3, 3-257-2, 3-263-1, 3-263-2, 3-264-1, 3-265-1, 3257-1, 3-258-1, 3-266-1, 3-264-2, 3-248-1, 3-259-1, 3-303-21, 3-254-2, 3-255-7, 4-331-22, 3-255-9, 3-297-15, 3-255-8, 3-256-4, 3-256-3, 3-304-1, 3-256-7, 4-331-3, 3-256-6, 3-256-8, 3-260-4, 3-257-12, 3-260-13, 3-262-12, 3-262-11, 3-2301, 3-230-2, 3-230-3, 3-230-4, 3-230-5, 3-231-1, 3-231-2, 3-231-3, 3-234-1, 3-234-2, 3-234-3, 3-234-4, 3-232-1, 3-232-1, 3-232-2, 3-233-1, 3-232-3, 3-233-2, 3-233-3, 3-235-2, 3-234-5, 3-246-1, 3-236-2, 3-235-3, 3-235-1, 3-237-1, 3-238-1, 3$260-5$ y $3-249-1$. 


\section{APÉNDICE 2}

RECAUDACIONES DE MILLONES, ALCABALAS Y CIENTOS EN CASTILLA, 1601-1700 (millones de maravedíes corrientes)

\begin{tabular}{|c|c|c|c|c|c|c|c|c|c|}
\hline Años & Alcabalas & Cientos & Millones & Total & Años & Alcabalas & Cientos & Millones & Total \\
\hline 1601 & 1.059 & & 551 & 1.610 & 1651 & 956 & 437 & 1.323 & 2.716 \\
\hline 1602 & 1.059 & & 611 & 1.670 & 1652 & 923 & 435 & 1.304 & 2.662 \\
\hline 1603 & 1.059 & & 866 & 1.925 & 1653 & 923 & 431 & 1.291 & 2.645 \\
\hline 1604 & 1.059 & & 969 & 2.028 & 1654 & 923 & 457 & 1.251 & 2.631 \\
\hline 1605 & 1.059 & & 881 & 1.940 & 1655 & 890 & 453 & 1.306 & 2.649 \\
\hline 1606 & 1.059 & & 791 & 1.850 & 1656 & 873 & 540 & 1.626 & 3.039 \\
\hline 1607 & 1.049 & & 775 & 1.824 & 1657 & 873 & 681 & 1.783 & 3.337 \\
\hline 1608 & 1.049 & & 776 & 1.825 & 1658 & 873 & 676 & 1.802 & 3.351 \\
\hline 1609 & 1.049 & & 742 & 1.791 & 1659 & 873 & 682 & 1.694 & 3.249 \\
\hline 1610 & 1.049 & & 751 & 1.800 & 1660 & 857 & 682 & 1.533 & 3.072 \\
\hline 1611 & 1.049 & & 809 & 1.858 & 1661 & 849 & 666 & 1.518 & 3.033 \\
\hline 1612 & 1.043 & & 799 & 1.842 & 1662 & 849 & 656 & 1.453 & 2.958 \\
\hline 1613 & 1.043 & & 779 & 1.822 & 1663 & 849 & 642 & 1.444 & 2.935 \\
\hline 1614 & 1.043 & & 773 & 1.816 & 1664 & 849 & 649 & 1.474 & 2.972 \\
\hline 1615 & 1.041 & & 730 & 1.771 & 1665 & 841 & 716 & 1.445 & 3.002 \\
\hline 1616 & 1.041 & & 724 & 1.765 & 1666 & 843 & 868 & 1.376 & 3.087 \\
\hline 1617 & 1.041 & & 659 & 1.700 & 1667 & 843 & 856 & 1.340 & 3.039 \\
\hline 1618 & 1.041 & & 631 & 1.672 & 1668 & 843 & 849 & 1.320 & 3.012 \\
\hline 1619 & 1.041 & & 598 & 1.639 & 1669 & 843 & 833 & 1.300 & 2.976 \\
\hline 1620 & 1.041 & & 737 & 1.778 & 1670 & 845 & 848 & 1.295 & 2.988 \\
\hline 1621 & 1.038 & & 726 & 1.764 & 1671 & 843 & 828 & 1.228 & 2.899 \\
\hline 1622 & 1.038 & & 721 & 1.759 & 1672 & 843 & 836 & 1.230 & 2.909 \\
\hline 1623 & 1.038 & & 723 & 1.761 & 1673 & 843 & 846 & 1.241 & 2.930 \\
\hline 1624 & 1.038 & & 746 & 1.784 & 1674 & 843 & 854 & 1.264 & 2.961 \\
\hline 1625 & 1.035 & & 758 & 1.793 & 1675 & 841 & 868 & 1.239 & 2.948 \\
\hline 1626 & 1.035 & & 979 & 2.014 & 1676 & 834 & 859 & 1.228 & 2.921 \\
\hline 1627 & 1.055 & & 1.004 & 2.059 & 1677 & 834 & 857 & 1.232 & 2.923 \\
\hline 1628 & 1.055 & & 987 & 2.042 & 1678 & 834 & 859 & 1.247 & 2.940 \\
\hline 1629 & 1.055 & & 893 & 1.948 & 1679 & 834 & 846 & 1.216 & 2.896 \\
\hline 1630 & 1.076 & & 796 & 1.872 & 1680 & 828 & 844 & 1.206 & 2.878 \\
\hline 1631 & 1.060 & & 497 & 1.557 & 1681 & 793 & 824 & 1.181 & 2.798 \\
\hline 1632 & 1.060 & & 158 & 1.218 & 1682 & 774 & 758 & 1.173 & 2.705 \\
\hline 1633 & 1.060 & & 1.047 & 2.107 & 1683 & 597 & 616 & 905 & 2.118 \\
\hline
\end{tabular}


APÉNDICE 2

RECAUDACIONES DE MILLONES, ALCABALAS Y CIENTOS EN CASTILLA, 1601-1700 (millones de maravedíes corrientes)

\begin{tabular}{|c|c|c|c|c|c|c|c|c|c|}
\hline Años & Alcabalas & Cientos & Millones & Total & Años & Alcabalas & Cientos & Millones & Total \\
\hline 1634 & 1.045 & & 1.043 & 2.088 & 1684 & 597 & 614 & 905 & 2.116 \\
\hline 1635 & 1.041 & & 1.210 & 2.251 & 1685 & 590 & 588 & 868 & 2.046 \\
\hline 1636 & 1.041 & & 1.286 & 2.327 & 1686 & 604 & 309 & 681 & 1.594 \\
\hline 1637 & 1.041 & & 1.245 & 2.286 & 1687 & 604 & 321 & 688 & 1.613 \\
\hline 1638 & 1.041 & & 1.595 & 2.636 & 1688 & 604 & 308 & 667 & 1.579 \\
\hline 1639 & 1.041 & 236 & 1.733 & 3.010 & 1689 & 604 & 305 & 663 & 1.572 \\
\hline 1640 & 1.038 & 246 & 1.958 & 3.242 & 1690 & 618 & 318 & 658 & 1.594 \\
\hline 1641 & 1.034 & 255 & 1.850 & 3.139 & 1691 & 636 & 325 & 661 & 1.622 \\
\hline 1642 & 1.030 & 349 & 1.681 & 3.060 & 1692 & 636 & 325 & 657 & 1.618 \\
\hline 1643 & 1.027 & 479 & 1.680 & 3.186 & 1693 & 636 & 322 & 660 & 1.618 \\
\hline 1644 & 1.027 & 492 & 1.645 & 3.164 & 1694 & 636 & 322 & 676 & 1.634 \\
\hline 1645 & 1.024 & 487 & 1.559 & 3.070 & 1695 & 654 & 332 & 683 & 1.669 \\
\hline 1646 & 1.024 & 487 & 1.584 & 3.095 & 1696 & 654 & 335 & 682 & 1.671 \\
\hline 1647 & 929 & 466 & 1.529 & 2.924 & 1697 & 654 & 339 & 733 & 1.726 \\
\hline 1648 & 929 & 465 & 1.477 & 2.871 & 1698 & 654 & 347 & 735 & 1.736 \\
\hline 1649 & 929 & 461 & 1.401 & 2.791 & 1699 & 654 & 358 & 735 & 1.747 \\
\hline 1650 & 834 & 454 & 1.343 & 2.631 & 1700 & 654 & 353 & 730 & 1.737 \\
\hline
\end{tabular}

